\title{
Low-temperature glass bonding for sensor applications using boron oxide thin films
}

\author{
Rob Legtenbergt, Siebe Bouwstra and Miko Elwenspoek \\ MESA Research Institute, University of Twente, PO Box 217, 7500 AE Enschede, \\ The Netherlands
}

Received 22 May 1991, accepted for publication 25 June 1991

tAddress to which all correspondence should be addressed: University of Twente, Faculty of Applied Physics, PO Box 217. 7500 AE Enschede, The Netherlands.

\begin{abstract}
Low-temperature glass bonding of silicon, silicon dioxide and silicon nitride is described. Boron oxide was used as the intermediate glass layer at a bonding temperature of $450^{\circ} \mathrm{C}$. First experiments indicate that due to reflow and deformation of the molten glass layer, bonding over metal patterns is possible, e.g. aluminium or chromium/gold. No voids are observed by examination of cleaved cross sections using optical microscopy or by $\mathrm{IR}$ transmission of bonded wafers. Scanning acoustic tomography, however, revealed regions of good, as well as regions of bad bonding quality. Bonding at low temperatures, with less critical demands for surface flatness, and the possibility of metalized electrical feedthrough will offer more process flexibility in the fabrication of sensors and actuators.
\end{abstract}

\section{Introduction}

Bonding technology is of growing importance for the fabrication of sensors, actuators and microstructures. The most widely used bonding techniques are anodic bonding $[1,2]$ and silicon fusion bonding $[3,4]$. Fusion bonding can only be used for bonding silicon and silicon oxide surfaces at high temperatures. Anodic bonding requires high electrical fields between a metal or silicon anode and a glass containing mobile ions. Diffused leads are necessary if electrical feedthrough is required. Both techniques demand particle-free and flat wafer surfaces.

The bonding technology presented in this paper is based on the melting of an intermediate glass film deposited on one or both of the wafers to be bonded [57]. The bonding temperature depends on the type of glass film used, and can be well below the eutectic temperature of aluminium and silicon. Mating of the wafers is accomplished by applying a force perpendicular to the bonding plane. Low-temperature glass bonding offers the possibility of bonding surfaces of various materials provided that the glass adheres well and that the applied materials remain stable at the bonding temperature. Another advantage is that during bonding the molten glass layer can be deformed, which may result in surface planarization [8]. In case of thin films sandwiched between silicon wafers, the influence of thermal mismatch is small.
For the intermediate glass layer, a large variety of commercially available low melting point glass fritts exist [9]. As a result of the work of L A Fields [7] and the availability in our laboratory we started this investigation using boron oxide as the intermediate glass layer. Boron oxide films were grown by atmospheric-pressure chemical vapor deposition at $425^{\circ} \mathrm{C}$ instead of deposition using solid source boron wafers at $1075^{\circ} \mathrm{C} \mathrm{[7].}$ Boron oxide has a melting point of $450^{\circ} \mathrm{C}$ and is compatible with IC-technology. In this paper we report on our first experiments. Bonding of silicon, silicon dioxide and silicon nitride and the possibility of metalized feedthrough of electrical connections were investigated.

\section{Experiments}

Bonding experiments were performed with 2-inch p-type silicon wafers covered with different thin films. During the experiments the presence of phosphorus was avoided because the formation of BPO4 would have resulted in a higher melting point [7].

Prior to bonding, wafers were cleaned by means of a two-step fuming nitric acid dip for $10 \mathrm{~min}$ followed by a 3 min deionized water rinsing step and spin drying. After cleaning, the glass layer was deposited on one of the wafers. Boron oxide was grown by atmospheric-pressure 
Table 1. Combinations of materials used in bonding experiments. The top wafer was coated with boron oxide.

\begin{tabular}{|c|c|c|c|c|}
\hline \multirow[t]{2}{*}{ Bottom wafer } & \multicolumn{4}{|c|}{ Top wafer } \\
\hline & $\begin{array}{l}\text { p-type } \\
\text { Si }\end{array}$ & $\begin{array}{l}\mathrm{SiO}_{2} \\
\text { wet }\end{array}$ & $\begin{array}{l}\mathrm{SiO}_{2} \\
\mathrm{dry}\end{array}$ & $\mathrm{Si}_{x} \mathrm{Ny}$ \\
\hline$p$-type Si & $x$ & $x$ & $x$ & $x$ \\
\hline $\mathrm{SiO}_{2}$ wet & $x$ & $x$ & $x$ & $x$ \\
\hline $\mathrm{SiO}_{2}^{2} \mathrm{dry}$ & $x$ & $x$ & $x$ & $x$ \\
\hline $\mathrm{Si}_{3} \mathrm{~N}_{4}$ & $x$ & $x$ & $x$ & $x$ \\
\hline $\operatorname{SiN}$ & $x$ & $x$ & $x$ & $x$ \\
\hline $\mathrm{SiO}_{2}-\mathrm{Al} 0.5 \mu \mathrm{m}$ & 一 & $x$ & $x$ & - \\
\hline $\mathrm{SiN}-\mathrm{Cr} / \mathrm{Au} 1.0 \mu \mathrm{m}$ & - & $x$ & $x$ & - \\
\hline
\end{tabular}

chemical vapor deposition (APCVD) in a horizontal hotplate bell-jar reactor. A gas mixture of $\mathrm{N}_{2}: \mathrm{O}_{2}: \mathrm{B}_{2} \mathrm{H}_{6}$ (2000 ppm) of respectively $6500: 70: 405 \mathrm{sccm}$ at a temperature of $425^{\circ} \mathrm{C}$ resulted in a deposition rate of $33 \mathrm{~nm}$ $\min ^{-1}$. Immediately after boron oxide deposition, both wafers were placed in a quartz holder under an applied weight, resulting in a pressure of $5 \mathrm{kPa}$, with the boron oxide covered wafer on top of the other. The assembly was put into an oven and slowly heated up to $450-475^{\circ} \mathrm{C}$ and kept at that temperature for 10 to $30 \mathrm{~min}$.

Table 1 shows the combinations of materials that have been applied for bonding experiments. Silicon oxides $\left(\mathrm{SiO}_{2}\right)$ were thermally grown and silicon-rich nitrides ( $\mathrm{SiN}$ ) were deposited by low-pressure chemical vapor deposition (LPCVD) from dichlorosilane and ammonia. Aluminium films were e-gun evaporated and chromium/gold films were sputtered. The glass thickness was varied from 1 to $5 \mu \mathrm{m}$. In the case of wafers covered with metal patterns a minimum glass thickness of $1.5 \mu \mathrm{m}$ was chosen.

\section{Results and discussion}

None of the wafer pairs used in bonding experiments could be peeled apart. This shows that low-temperature glass bonding of silicon p-type wafers and wafers covered by silicon oxide or silicon nitride, using APCVD boron oxide, is possible. Wafers covered by $0.5 \mu \mathrm{m}$ aluminium or $1.0 \mu \mathrm{m}$ chromium/gold patterns were also bonded. Glass layer thicknesses ranging from 1 to $5 \mu \mathrm{m}$ showed little influence on bonding effectiveness. For thinner films, however, surface topography and dust particles may affect the bonding quality. Varying the bonding time from 10 to $30 \mathrm{~min}$ and the bonding temperature from 450 to $475^{\circ} \mathrm{C}$ also showed little effect.

We noticed that, during boron oxide deposition at $425^{\circ} \mathrm{C}$, wafers kept sticking at the hot plate of the reactor after multiple deposition runs. This indicates that bonding also occurs at lower temperatures.

Glass reflow was observed after bonding wafers with anisotropically etched $\mathrm{V}$-grooves and openings. Especially for thick glass films, using long bonding times and high temperatures, reflow was visible (see figure 1).

For bond characterization several methods have been

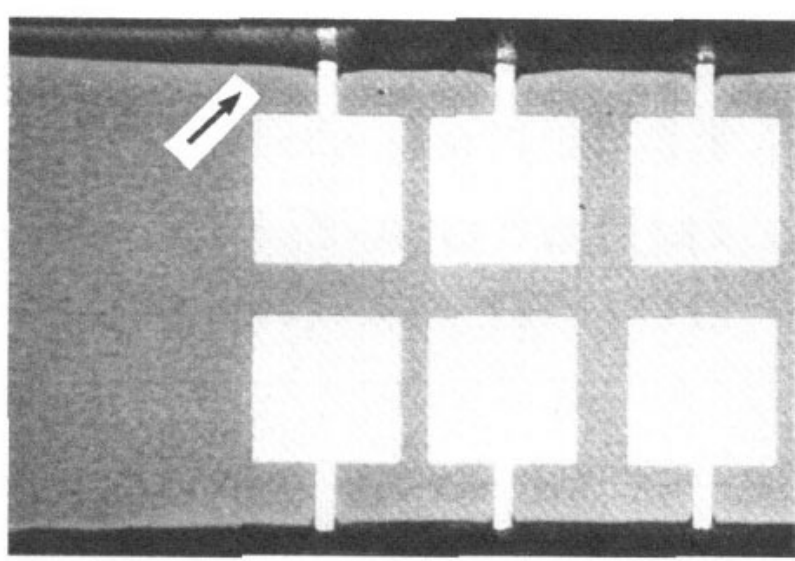

Figure 1. Glass reflow (see arrow) of a $5 \mu \mathrm{m}$ thick glass layer from the top wafer over SiN and $\mathrm{Cr} / \mathrm{Au}$ patterns at the bottom wafer after bonding at $475^{\circ} \mathrm{C}$ for $30 \mathrm{~min}$. Bonding pad dimensions are $150 \times 150 \mathrm{\mu m}^{2}$.

used. Wafers have been cleaved into narrow strips and the interface has been examined under a microscope. No voids could be observed. Figure 2 shows a SEM photograph of a cleaved cross section showing the boron oxide film between both wafers.

Bonded wafers were also examined by IR transmission using an infrared laser $(\lambda=1.32 \mu \mathrm{m})$ and an IR sensitive TV camera $(\lambda=0.5-1.8 \mu \mathrm{m})$. Voids are indicated by interference rings with a separation of $\lambda / 2 n(\lambda=\mathrm{IR}$ wavelength and $n=$ refractive index of the intermediate layer). Some samples have been examined by scanning acoustic tomography [10] in reflected pulse mode at a frequency of $30 \mathrm{MHz}$ with a lateral resolution of about $40 \mu \mathrm{m}$. Figure 3 shows the IR-transmission image (left) and the acoustic image (right) of an unsuccessful anodic bonding to demonstrate the interpretation.

In the IR-transmission image of the anodic bonding two interference patterns can be recognized; a vague pattern over the entire wafer and a pattern with more contrast. The vague interference patterns are due to thickness variations of the $4 \mu \mathrm{m}$ thick pyrex layer. The dark interference rings are the result of non-bonded

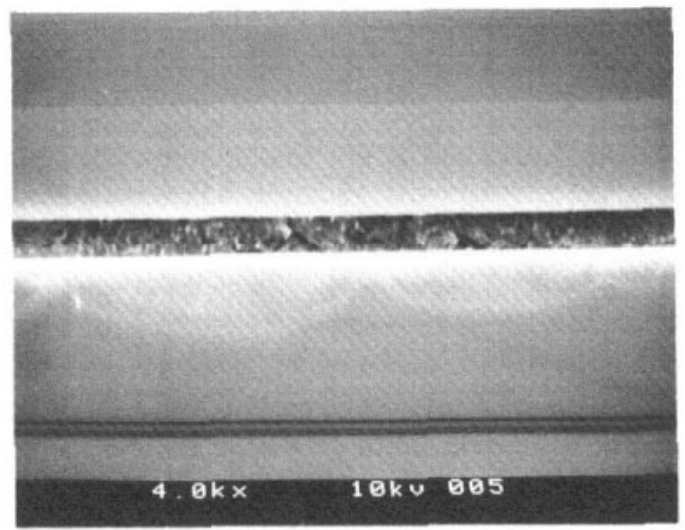

Figure 2. SEM photograph of a cleaved cross section showing the boron oxide film adhering to both silicon surfaces. Boron oxide film is $1.5 \mu \mathrm{m}$ thick. 


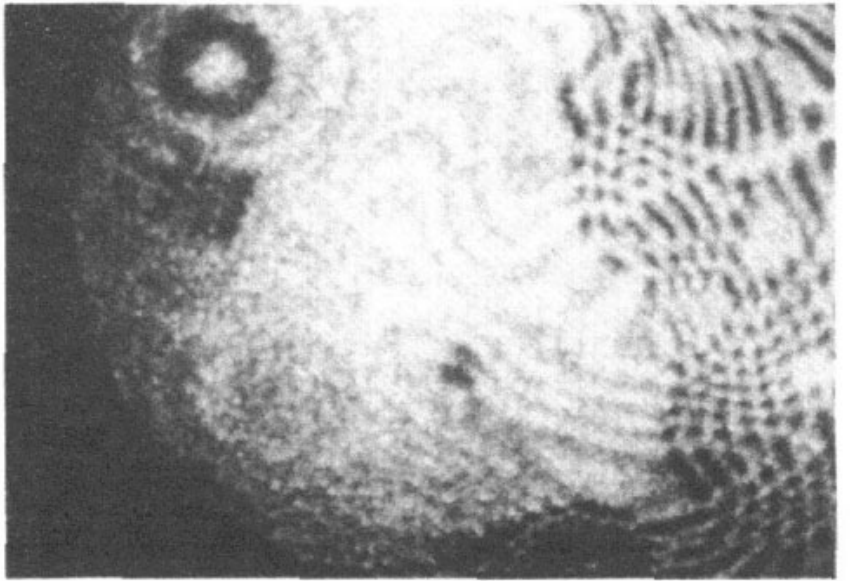

(a)

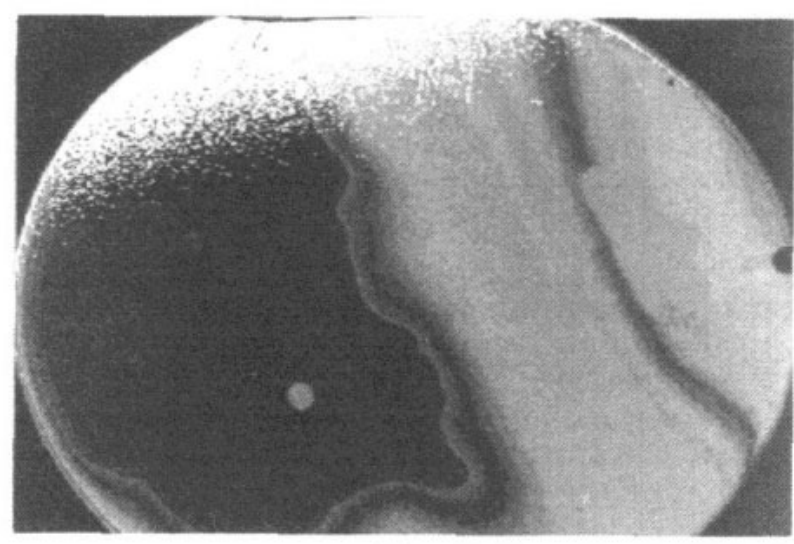

(b)

Figure 3. IR-transmission image (a) and acoustic image (b) of an unsuccessful anodic bonding with a $4 \mu \mathrm{m}$ thick pyrex film.

regions; the additional gap between the wafers causes an interference pattern with more contrast.

In the case of acoustic imaging, dark areas indicate regions of good bonding. In the light areas the reflected acoustic signal indicated voids between the wafers. In case of anodic bonding both methods showed the same voids, regions of bonding failure and successful bonding areas.

Figure 4 shows the IR-transmission (left) and acoustic (right) image of a typical low-temperature glass bonded wafer pair. The vertical metal pattern lines between the wafers are visible with IR transmission but, in our case, are not detectable by the acoustic method.

IR transmission of low-temperature bonded wafers shows only the vague interference patterns due to thickness variations in the boron oxide film. No voids or nonbonded regions are observed. This is also the case with the wafers covered with metal patterns. Apparently glass deformation and reflow results in the filling of surface roughness, the covering of steps and the enclosing of dust particles.

However, the acoustic measurement of the glass bonded samples shows light and dark regions. The

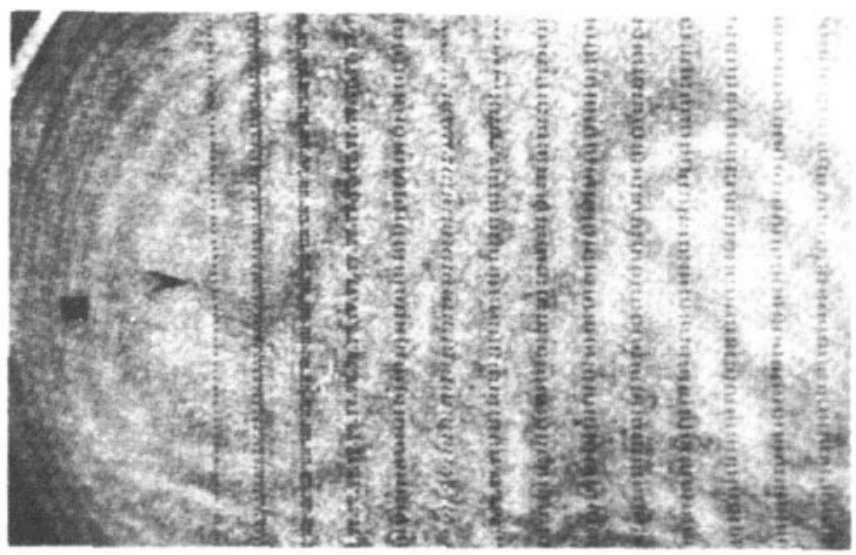

(a)

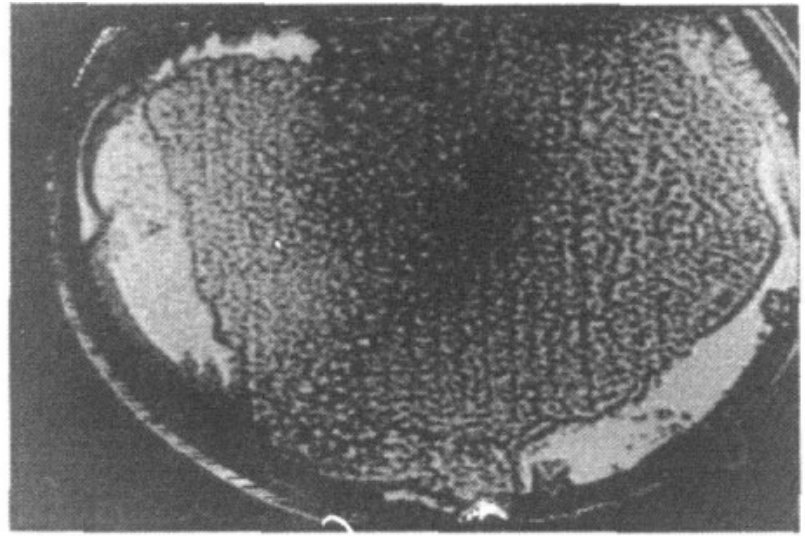

(b)

Figure 4. IR-transmission image (a) and acoustic image (b) of a typical low-temperature glass bonding. A silicon wafer covered with silicon nitride and $0.5 \mu \mathrm{m}$ thick aluminium patterns bonded at $450^{\circ} \mathrm{C}$ to a silicon-oxide covered wafer with a $3 \mu \mathrm{m}$ thick boron-oxide layer.

acoustic images give more detailed information about the bonding quality but the interpretation is difficult. Dark regions again indicate good bonding. The light regions are the result of bad acoustic contact between both wafers. The reflected acoustic signal in most of these regions showed a sinusoidal decay with low attenuation, which is characteristic for weak fusions $[11,12]$. This indicates that the surfaces in these regions do stick together with weak bonding strength.

We observed that bonded wafers immersed in water at room temperature for a few days remain stuck together but that, after cleaving, unbounded areas showed up. This may result from the fact that boron oxide is soluble in water, alcohols and esters [13] and that the sandwiched glass film slowly dissolves. This seriously limits the applications of boron oxide for bonding in sensor technology and calls for the investigation of other glass types. No degradation of bonding quality was observed when samples were kept under normal room conditions.

Experiments to investigate the sealing quality and bonding strength have not been performed yet. References $[6,7]$ show that good seals are possible. 


\section{Conclusions}

First experiments have shown that low-temperature glass bonding of p-type silicon, silicon dioxide and silicon (rich) nitride both with and without aluminium or chromium/gold patterns using APCVD boron oxide is possible. No voids are observed by examination of cleaved cross sections using optical microscopy or by IR transmission of bonded wafers. This indicates that during bonding the molten glass layer is deformed resulting in planarization of the surface topography, covering steps and enclosing dust particles. Scanning acoustic tomography showed regions of good bonding as well as regions with bad bonding quality. Due to the solubility of boron oxide in water and the necessity to avoid phosphorus the application of this glass type in bonding, for the fabrication of sensors, is limited.

However, low temperature glass bonding continues to be a promising technology; it offers the possibility of bonding various materials with less critical demands for surface topography and clean room environment and makes feedthrough of metalized electrical connections possible. This results in a larger process flexibility for the fabrication of sensors and actuators. Further research will be focussed on other low-melting point glasses and improvement of the bonding quality.

\section{Acknowledgments}

We appreciate the permission of Frans van de Pol for the use of his anodically bonded wafers for comparison. We are grateful to John van Oijen from Philips Research Laboratories, Eindhoven, The Netherlands, for making the scanning acoustic tomography images and his help with the interpretation of the results.

\section{References}

[1] Wallis G and Pomerantz D I 1969 Field assisted glassmetal sealing J. Appl. Phys. 40 3946-9

[2] Knecht T A 1987 Bonding techniques for solid state pressure sensors Proc. Int. Conf. Solid-State Sensors and Actuators (Transducers '87) (Tokyo, Japan. 1987) $\mathrm{p} 95-8$

[3] Lasky J B 1986 Wafer bonding for silicon on insulator Appl. Phys. Lett. 48 78-80

[4] Barth P W 1990 Silicon fusion bonding for fabrication of sensors, actuators and microstructures Sensors \& Actuators A21-A23 919-26

[5] Bassous E 1978 Fabrication of novel three-dimensional microstructures by the anisotropic etching of (100) and (110) silicon IEEE Trans. on Electron Dev. ED-25 1178-85

[6] Ko W H, Suminto J T and Yeh G J 1985 Bonding techniques for microsensors Micromachining and micropackaging of transducers ed C D Fung et al (New York: Elsevier) p 57-8

[7] Fields L A and Muller R S 1990 Fusing silicon wafers with low melting temperature glass Sensors \& Actuators A21-A23 919-26

[8] Kern W and Schnable G L 1982 Chemically vapordeposited borophosphosilicate glasses for silicon device applications $R C A$ Review $43423-47$

[9] Schott product information, No. 4823/1d Glaslöte mit Schottglass

[10] Quate C F 1976 Imaging using lenses Acoustic imaging ed G Wade (New York: Plenum) p 241-305

[11] van Oijen J G W P private communications

[12] Hain R 1988 Resistivity testing of spot welds challenges ultrasonics Welding Journal 67 46-50

[13] Handbook of chemistry and physics, 67th edn 1986-7 (Boca Raton, FL: Chemical Rubber Company) p B-77 